\title{
Kemampuan Berpikir Logis dan Penguasaan Kosa kata Bahasa Jerman
}

\author{
Hesti Lestari', Misnawaty Usman² dan Hasmawati ${ }^{3}$ \\ Fakultas Bahasa dan Sastra, Universitas Negeri Makassar ${ }^{1,2,3}$ \\ E-mail: lestarihesti114@gmail.com
}

\begin{abstract}
There are many factors that can influence students' vocabulary mastery in foreign language learning. This study aims to determine the relationship between logical thinking skills and students' mastery of German vocabulary. Research is an experimental study involving only the experimental class without the control class. Data collection techniques are done through writing test and logical thinking test in the form of Intelligent Structure Test (IST). The sample in this study were 21 high school students selected through random sampling techniques. The results of the analysis of this study indicate that there is a significant relationship between the ability to think logically with students' mastery of German vocabulary. Students who have good critical thinking skills, tend to more easily remember and understand new vocabulary in learning foreign languages.
\end{abstract}

Keywords: Vocabulary Mastery, Logical Thinking, German Language, German Vocabulary

https://ojs.unm.ac.id/eralingua

\section{PENDAHULUAN}

Penguasaan kosakata bagi pembelajar bahasa asing adalah hal yang sangat penting karena mempengaruhi kemampuan berbahasa lainnya baik itu kemampuan reseptif maupun kemampuan produktif (Abrar dkk., 2018; Hidayati, 2018; Madya dkk., 2018; Schmitt, 2019). Jika pembelajar tidak memiliki penguasaan kosakata yang baik, maka siswa akan megalami kesulitan dalam menyimak, berbicara, menulis dan membaca. Semakin banyak kosakata yang dikuasai oleh pembelajar maka tingkat penguasaan keempat kompetensi tersebut semakin menunjukkan kualitas siswa tersebut.

Jumlah kosa-kata bahasa Jerman yang harus dikuasai siswa seperti yang tertulis dalam kompetensi dasar, kompetensi inti, dan indikator mata pelajaran bahasa Jerman yaitu untuk kelas $X$ semester 1 menguasai kurang lebih 250 kosa-kata, semester 2 kurang lebih 550 kosakata, kelas XI semester 1 kurang lebih 800 kosakata, semester 2 kurang lebih 1000 kosakata. Sedangkan Dryden dan Vos (Samaa, 2015) menyatakan bahwa jumlah kosakata yang diharapkan sebanyak 1000-3000 kosakata dasar secara pasif agar siswa mampu menggunakan bahasa asing yang mereka pelajari. Maka dari itu, salah satu hal yang harus difokuskan guru dalam pengajaran bahasa asing adalah bagaimana agar siswa menguasai kosa kata sebanyak mungkin.

Penelitian yang fokus dalam meningkatkan penguasaan kosa kata siswa dalam pembelajaran bahasa asing telah banyak dilakukan oleh peneliti-peneliti sebelumnya (Sahrin \& Hasan, 2019; Feng dkk., 2019; Hussain, 2018; Nasution, 2018). Penelitian tersebut menunjukkan bahwa terdapat beberapa hal yang dapat dilakukan dalam 
meningkatkan penguasaan kosa kata siswa baik itu menerapkan model pembelajaran yang sesuai, mengembangkan bahan ajar, serta menggunakan sarana prasarana belajar yang dapat mendukung. Salah satu variabel yang dapat berpengaruh pada penguasaan kosa kata siswa adalah kemampuan berpikir logis (Kusumawati dkk., 2019; Wulandari, 2018; Wei, 2018).

Berpikir logis mempengaruhi penguasaan kosakata siswa terutama dalam proses menulis kalimat bahasa Jerman. Berpikir logis dalam tulisan dapat dilihat dari cara siswa memilih kosakata untuk menyampaikan ide dan gagasannya dalam bentuk kalimat yang efektif. Maka dari itu, berpikir logis sangat dibutuhkan dalam penguasaan kosakata untuk menulis suatu kalimat yang efektif. Beberapa penelitian sebelumnya fokus mengkaji kemampuan berpiikir logis terhadap penguasaan kosa kata bahasa Inggris, atau kemampuan berpikir logis terhadap penguasaan kosa kata bahasa pertama dan bahasa kedua.

Penelitian ini fokus untuk mengkaji bagaimana pengaruh berpikir logis terhadap penguasaan kosa kata bahasa Jerman siswa. Bahasa Jerman merupakan salah satu bahasa asing yang dipelajari di tingkat sekolah menengah atas. Salah satu kelemahan siswa dalam mempelajari bahasa Jerman adalah dari segi pemahaman kosa kata yang rendah. Hal tersebut disebabkan bahasa Jerman merupakan hal yang baru bagi siswa tidak seperti halnya dengan bahasa Inggris. Berdasarkan latar belakang tersebut, maka fokus penelitian ini ialah apakah ada pengaruh kemampuan berpikiri kritis siswa terhadap penguasaan kosa kata bahasa Jerman siswa.

\section{KAJIAN PUSTAKA}

\section{Berpikir Logis}

Berpikir logis adalah suatu proses berpikir yang sesuai dengan logika, rasional dan dapat diterima secara umum. Berpikir logis dapat didefinisikan sebagai kemampuan untuk menghubungkan dua atau lebih komponen atau faktor dalam sebuah hubungan yang secara umum diterima argumentasi validitasnya. Berpikir logis adalah aktivitas yang terkait dengan pengambilan keputusan dan pemecahan masalah yang kompleks. Kemampuan berpikir logis adalah kemampuan dalam menggunakan peryataan-pernyataan berupa gagasan, dan diuraikan secara sistematis. Berpikir logis juga dapat didefenisikan sebagai suatu proses menalar tentang suatu objek dengan menghubungkan serangkaian pendapat untuk sampai pada sebuah kesimpulan menurut aturan-aturan logika.

Penelitian menegnai berpikir logis dalam pembelajaran telah banyak dilakukan oleh peneliti-peneliti sebelumnya Rahman dkk. (2018), Gokhale \& Machina (2018), Ash-Shiddieqy dkk. (2018). Dari beberapa penelitian tersebut dapat disimpulkan bahwa berpikir logis merupakan suatu proses berpikir dengan berbicara pada diri sendiri dalam hal ini mempertimbangkan, menganalisis dan menghubungkan pernyataan satu dengan pernyataan lainnya. Seorang individu yang berpikir logis dapat menggunakan ide dan gagasannya secara sistematis sehingga pendapat yang disampaikan dapat diterima. 


\section{Penguasaan Kosakata}

Kosakata merupakan salah satu unit bahasa yang mempunyai peranan penting dalam berbahasa karena dalam komunikasi kata-kata menjadi objek yang disatukan dalam suatu konstruksi yang lebih besar berdasarkan kaidah-kaidah yang ada dalam bahasa tersebut. Kosakata merupakan semua kata dalam sebuah bahasa atau bidang bahasa. Suatu bahasa tidak dapat terlepas dari kosa kata karena kosa kata merupakan inti dari sebuah bahasa. Beberapa penelitian yang mengkaji penguasaan kosa kata seperti Alfitri dkk. (2018), Mufidah dkk. (2019), Tanjung dkk. (2018), Jatikusumo \& Hidayat (2019) menunjukkan bahwa terdapat beberapa strategi yang dapat dilakukan untuk memperluas kosakata seseorang antara lain : "(1) Melalui proses belajar, perluasan kosakata melalui proses belajar dilakukan di lembagalembaga pendidikan; (2) Melalui konteks, pengertian kata yang diperoleh dengan cara itu tergantung dari ketajaman orang yang mengamati teks itu; (3) Melalui kamus, kamus menyuguhkan sebuah daftar kata; (4) Menganalisa kata, menganalisa kata yang muncul dalam bentuk gabungan.

\section{METODE PENELITIAN}

Terdapat 2 variabel dalam penelitian ini yaitu kemampuan berpikir logis siswa sebagai variabel bebas $(X)$ dan penguasaan kosakata bahasa Jerman siswa sebagai variabel terikat $(\mathrm{Y})$. Tes berpikir logis yang digunakan dalam penelitian ini adalah tes Intelligenz Structure Test (IST). Penelitian ini menggunakan 4 subtes dari IST yang sesuai dengan tujuan penelitian yaitu untuk mengukur kemampuan berpikir logis, di antaranya adalah Satzerganzung (melengkapi kalimat), Analogien (padanan kata), Reichen Aufgaben (hitungan sederhana), dan (Gemeinsamkeiten) (persamaan sifat). Tes yang diberikan dalam bentuk soal pilihan ganda dengan jumlah 20 butir soal yang diberi skor 1 untuk jawaban yang benar dan o untuk jawaban yang salah. Tes penguasaan kosakata dalam penelitian ini adalah tes yang diberikan untuk mengukur kemampuan siswa dalam memahami dan menggunakan kata kerja, kata sifat, kata tanya, kata penghubung dan kata benda yang berjumlah 30 butir soal dengan tema Essen und Trinken. Data penelitian ini diolah dengan menggunakan teknik analisis statistik deskriptif dan statistik inferensial.

\section{HASIL DAN PEMBAHASAN}

\section{Hasil Analisis Data Tes Kemampuan Berpikir Logis}

Data tes kemampuan berpikir logis diperoleh dari hasil tes yang diberikan kepada 21 siswa kelas XI IPS 3 SMA Negeri 3 Sinjai. Skor minimal yang diperoleh siswa adalah o dan skor maksimal adalah 20. Berdasarkan data penelitian yang telah diolah untuk kemampuan berpikir logis, nilai terendah yang dicapai siswa adalah 20 dan nilai tertinggi yang dicapai siswa adalah 65. dari 21 siswa yang menjadi sampel diperoleh 3 siswa (14,29\%) berada pada interval 20-29, 3 siswa (14,29\%) berada pada interval 3039, 4 siswa (19,04\%) berada pada interval 40-49, 7 siswa (33,34\%) berada pada interval 50-59, 4 siswa (19,04\%) berada pada interval 60-69. Dari data tersebut dinyatakan bahwa kelas interval yang memiliki frekuensi tertinggi berada pada interval 50-59 dengan frekuensi sebanyak 7 siswa. Hal ini menun-jukkan bahwa tingkat kemam-puan berpikir logis siswa kelas XI IPS 3 SMA Negeri 3 Sinjai berada pada kategori 
pemahaman cukup dengan skor rata-rata 45 dengan persentase sebesar 69,23\% sehingga dapat disimpulkan bahwa kemampuan berpikir logis siswa sudah cukup.

\section{Hasil Analisis Data Tes Penguasaan Kosakata}

Data tes penguasaan kosakata merupakan hasil tes penguasaan kosakata bahasa Jerman yang diukur dengan menggunakan tes essay dan pilihan ganda diberikan kepada semua sampel. Berdasarkan data penelitian yang telah diolah untuk penguasaan kosakata bahasa Jerman, nilai terendah yang dicapai siswa adalah 32 dan nilai tertinggi yang dicapai siswa adalah 66. dari 21 siswa yang menjadi sampel diperoleh 1 siswa (4,77\%) berada pada interval 32-39, 4 siswa (19,04\%) berada pada interval 40-47, 4 siswa (19,04\%) pada interval 48-55, 8 siswa $(38,10 \%)$ berada pada interval 56-62, 4 siswa (19,04\%) berada pada interval 63-70. Dari data tersebut dinyatakan bahwa kelas interval tertinggi berada pada interval 56-62 dengan frekuensi sebanyak 8 siswa. Hal ini menunjukkan bahwa tingkat peng-uasaan kosakata bahasa Jerman siswa kelas XI IPS 3 SMA Negeri 3 Sinjai berada pada kategori baik dengan skor rata-rata 54,60 dengan per-sentase sebesar $82,70 \%$ sehingga dapat disimpulkan bahwa penguasaan kosakata siswa masih perlu ditingkatkan dengan banyak memberi soal latihan berbahasa Jerman kepada siswa.

Berdasarkan hasil analisis Korelasi Product Moment diperoleh koefisien korelasi sebesar 0,574. Untuk mengetahui bahwa koefisien korelasi yang signifikan dan dapat digunakan sebagai kesimpulan terhadap populasi maka koefisien korelasi hitung (rh) sebesar 0,574 dibandingkan dengan koefisien korelasi tabel (rt) sebesar 0,433 pada taraf signifikan $5 \%$ yang terdapat pada tabel nilai $r$ Product Moment. Dengan demikian dinyatakan ada hubungan positif yang signifikan antara kemampuan berpikir logis $(\mathrm{X}$ ) dengan penguasaan kosakata bahasa Jerman $(\mathrm{Y})$ dengan kekuatan koe-fisien korelasi kedua variabel ter-golong dalam ketegori sedang.

Kemampuan berpikir logis siswa berperan penting terhadap penguasaan kosakata bahasa Jerman. Dalam menulis kalimat maka dibutuhkan berpikir logis untuk memahami, membandingkan, dan mempertimbangkan kosakata yang akan digunakan. Jika seorang siswa yang memahami kosakata dengan daya nalarnya atau berpikir logis maka kosakata tersebut akan selalu diingat oleh siswa, karena siswa telah mengalami proses perkembangan berpikir di mana, mengapa dan bagai-mana kosakata tersebut digunakan dalam kalimat sehingga meng-hasilkan suatu pernyataan yang logis atau masuk akal. Berbeda dengan siswa yang hanya menghafal, ketika menghadapi ujian atau soal yang ingin diselesaikan, siswa akan mengalami kesulitan dalam mengoperasionalkan kosakata yang dihafal untuk menyelesaikan soal.

\section{KESIMPULAN}

Berdasarkan hasil penyajian data, dapat disimpulkan bahwa kemampuan berpikir kritis siswa menjadi salah satu faktor yang dapat mempengaruhi penguasaan kosa kata siswa khususnya penguasaan kosa kata bahasa Jerman. Rendahnya kemampuan siswa dalam memahami kosa kata bahasa Jerman, salah satu kecenderungannya disebabkan karena metode pengajaran yang diimplementasikan guru tidak berorientasi pada peningkatan kemampuan berpikir logis siswa. Maka dari itu, pengajar bahasa Jerman disarankan untuk mengembangkan model pembelajaran 
yang dapat berorientasi peningkatan kemampuan berpikir logis siswa, sehingga hal tersebut nantinya memudahkan siswa dalam memahami kosa kata bahasa Jerman.

\section{DAFTAR PUSTAKA}

Abrar, M., Mukminin, A., Habibi, A., Asyrafi, F., Makmur, M., \& Marzulina, L. (2018). "If our English isn'ta language, what is it?" Indonesian EFL Student Teachers' Challenges Speaking English. The Qualitative Report, 23(1), 129-145.

Alfitri, R., Iswari, M., \& Kasiyati, K. (2018). Meningkatkan Pembendaharaan Kata Melalui Media Kata Bergambar bagi Anak Tunarungu. Jurnal Pendidikan Kebutuhan Khusus, 2(1), 40-45.

Ash-Shiddieqy, M. H., Suparmi, A., \& Sunarno, W. (2018, April). The effectiveness of module based on guided inquiry method to improve students' logical thinking ability. In Journal of Physics: Conference Series (Vol. 1006, No. 1, p. 012001). IOP Publishing.

Feng, C. K., Beng, K. Y., \& Yunus, M. M. (2019). The usage of Wopzzle in Enriching Pupils' Mastery of Vocabulary Learnt. International Journal of Academic Research In Business And Social Sciences, 9(1).

Gokhale, A., \& Machina, K. (2018). Guided Online Group Discussion Enhances Student Critical Thinking Skills. International Journal on E-Learning, 17(2), 157-173.

Hidayati, N. (2018). Using a Teaching Media of "Homophone Stories "to Improve Students' Vocabulary Mastery: a Case of Seventh Grade Students at SMPN 1 Kranggan in Academic Year 2014/2015. ETERNAL (English Teaching Journal), 6(2).

Hussain, Z. (2018). The Effects Of Ict-Based Learning On Students'vocabulary Mastery In Junior High Schools In Bandung. International Journal of Education, 10(2), 149-156.

Jatikusumo, D., \& Hidayat, R. R. (2019). Pembelajaran Bahasa Inggris Melalui Permainan Tebak Kata dengan Web Crawler Menggunakan Android. Computatio: Journal of Computer Science and Information Systems, 3(1), 2130

Kusumastuti, I., Fauziati, E., \& Marmanto, S. (2019, May). Revealing Teachers'beliefs Of Higher Order Thinking Skills In Teaching Reading At Junior High School. In English Language and Literature International Conference (ELLiC) Proceedings (Vol. 3, pp. 155-162).

Madya, S., Hamied, F. A., Renandya, W. A., Coombe, C., \& Basthomi, Y. (2018). Improving learners' vocabulary mastery through the use of scaffolding strategies while storytelling in an EFL multiethnic classroom. In ELT in Asia in the Digital Era: Global Citizenship and Identity (pp. 151-158). Routledge

Mufidah, N., Salamah, U., Muthoharoh, I., \& Islamy, M. I. (2019). HYBRID LEARNING DALAM PEMBELAJARAN KOSA KATA BAHASA ARAB PADA ANAK BERBANTUAN MEDIA AL-MUTHO. journal AL-MUDARRIS, 2(1), 40-52.

Nasution, M. (2018, July). The Effect of Team Games Tournament (TGT) Method Toward Vocabulary Mastery at the Tenth Grade Students of Hgh School 1 Padangsidimpuan. In IOP Conference Series: Earth and Environmental Science (Vol. 175, No. 1, p. 012087). IOP Publishing 
Rahman, A., Usman, M., \& Ahmar, A. S. (2018, June). The Development of Android and Web-based Logical Thinking Measurement Tools as an Alternative Solution for Research Instruments. In Journal of Physics: Conference Series (Vol. 1028, No.1, p. 012168). IOP Publishing.

Regiana, D. (2012). Hubungan kemampuan berpikir logis dan kemampuan menulis teks bahasa Jerman siswa kelas XII SMA Negeri 15 Bandung. Universitas Pendidikan Indonesia. Skripsi: Repository.upi.edu.

Sahrin, V., \& Hasan, M. (2019). Increasing Students'vocabulary Acquisition by Master and Mastery Cards Game. JOALL (Journal of Applied Linguistics \& Literature), 4(1), 69-76.

Samaa, M. P. (2015). Hubungan Penguasaan Kosakata dengan Keterampilan Menulis Karangan Sederhana bahasa Jerman siswa kelas XI SMAN 2 RANTEPAO Kabupaten Toraja Utara. Makassar: Perpustakaan FBS UNM.

Schmitt, N. (2019). Understanding vocabulary acquisition, instruction, and assessment: A research agenda. Language Teaching, 52(2), 261-274.

Tanjung, R. R., Sukma, E., \& Miaz, Y. (2018). Hubungan Penguasaan Kosakata dengan Kemampuan Membaca Pemahaman Peserta Didik Kelas III SD. e-Journal Pembelajaran Inovasi, Jurnal Ilmiah Pendidikan Dasar, 6(1).

Wei, Y. (2018). Cultivating Critical Thinking Ability In BTI In China. Indonesian EFL Journal, 4(2), 90-98.

Wulandari, W. (2018). The Effects Of Vocabulary Mastery and Logical Thinking towards Student's Listening Skill at Private Vocational High Schools in East Jakarta. Scope: Journal of English Language Teaching, 1(02), 212-218. 